\title{
Forgiftning med karbonmonoksid og cyanidgass ved brann
}

KLINISK OVERSIKT

ODYSSEAS PAPALEXIOU ØKLAND

E-post: odyokl@gmail.com

Universitetet i Oslo

Han har bidratt med litteratursøk, idé, utforming og utarbeiding av manus.

Odysseas Papalexiou $\emptyset$ kland er medisinstudent.

Forfatteren har fylt ut ICMJE-skjemaet og oppgir ingen interessekonflikter.

\section{ESPEN ROSTRUP NAKSTAD}

Akuttmedisinsk avdeling

Oslo universitetssykehus

Han har bidratt med utforming, utarbeiding av manus og figurer.

Espen Rostrup Nakstad er ph.d., spesialist i indremedisin og i lungesykdommer og er overlege. Han leder Nasjonal behandlingstjeneste for CBRNE-medisin.

Forfatteren har fylt ut ICMJE-skjemaet og oppgir ingen interessekonflikter.

\section{HELGE OPDAHL}

Akuttmedisinsk avdeling

Oslo universitetssykehus

Han har bidratt med idé, utforming, utarbeiding og revisjon av manus.

Helge Opdahl er dr.med., spesialist i anestesiologi og tidligere overlege. Han er tidligere leder av Nasjonal behandlingstjeneste for CBRNE-medisin.

Forfatteren har fylt ut ICMJE-skjemaet og oppgir følgende interessekonflikter: Han har mottatt konsulenthonorar fra Linde.

Akutt forgiftning forårsaket av karbonmonoksid og andre giftige stoffer er den hyppigste dødsårsaken ved branner og kan foreligge uten tegn på ytre skade. Livstruende symptomer kan oppstå umiddelbart, som ved cyanidforgiftning, eller over noe lengre tid, som ved karbonmonoksidforgiftning. Alvorlige inhalasjonsskader kan også forekomme uavhengig av systemisk forgiftning og bør alltid mistenkes hos pasienter med sot $i$ ansikt og luftveier eller heshet og pipende respirasjon.

I perioden 1979-2018 omkom gjennomsnittlig 62 personer i brann hvert år i Norge, med en nedgang de siste fem årene til 39 årlige dødsfall (1). De fleste brannrelaterte skader skyldes ikke primære hudbrannskader, men røykforgiftning oppstått i lukkede rom, som boliger, utesteder, konsertlokaler og veitunneler (2). Forgiftning med karbonmonoksid utgjør tallmessig den største faren, men cyanidgass i dødelige konsentrasjoner kan også frigjøres ved forbrenning av plastholdige stoffer (polyuretan), slik det ble fastslått hos 18 omkomne etter brannen i fergen Scandinavian Star i 1990 (3).

Denne artikkelen er ment å belyse klinisk relevante momenter ved karbonmonoksid- og 
cyanidforgiftning ved eksponering for brannrøyk og bygger på strukturerte litteratursøk i forbindelse med førsteforfatters prosjektoppgave og medforfatternes erfaringer fra Akuttmedisinsk avdeling og CBRNE-senteret ved Oslo universitetssykehus.

\section{Brannrøykens skadepotensial}

Brannrøyk dannes gjennom forbrenning der oksygen forbrukes og nye toksiske gasser produseres. Inhalasjon kan gi lokal vevsskade i luftveiene. I øvre luftveier kan det oppstå lokal termal skade, oftest supraglottisk. I nedre luftveier kan irriterende gasser og sotpartikler gi hypoksemi ved å okkludere luftveier eller skade vevet direkte, eller fremkalle en inflammatorisk respons med bronkospasme og eksudat som medfører et misforhold mellom ventilasjon og perfusjon (4).

Giftige gasser og aerosoler som tas opp i blodet, kan også gi systemisk påvirkning. Karbonmonoksid (CO, kullos) og hydrogencyanid (HCN, blåsyregass) er de viktigste av de systemtoksiske gassene (4). Karbonmonoksid dannes i oksygenfattig miljø ved ufullstendig forbrenning av karboner, mens hydrogencyanid dannes ved forbrenning av plast, syntetisk gummi og annet (5).

\section{Patofysiologi}

De systemiske effektene av karbonmonoksid og hydrogencyanid bør forstås på bakgrunn av hvordan de endrer organismens oksygenomsetning. For at aerob metabolisme skal være mulig, må tilstrekkelig mengde $\mathrm{O}_{2}$ transporteres med blodet fra lungene til cellene. Videre er man avhengig av normal mitokondriefunksjon for å utnytte oksygenet.

Karbonmonoksid hemmer oksygentransporten ved å hindre at $\mathrm{O}_{2}$ bindes til hemoglobinets $\mathrm{Hb}$ ) hemegrupper som oksyhemoglobin $\left(\mathrm{O}_{2} \mathrm{Hb}\right)$. Hemmingen skjer ved at karbonmonoksidmolekylene binder seg til det toverdige jernet $\left(\mathrm{Fe}^{2+}\right)$ i Hb-molekylene med mer enn 210 ganger sterkere affinitet enn $\mathrm{O}_{2}(6)$. I nærvær av karbonmonoksid dannes dermed betydelige mengder karboksyhemoglobin $(\mathrm{COHb})$ mens $\mathrm{O}_{2} \mathrm{Hb}$ synker tilsvarende. Oksygenforsyningen til cellene reduseres derfor i takt med økningen av $\mathrm{COHb}$.

I tillegg vil binding av karbonmonoksid til ett eller flere bindingspunkter på Hb-molekylet også øke gjenværende hemegruppers affinitet for oksygen. Dermed løsner $\mathrm{O}_{2}$-molekylene vanskeligere fra $\mathrm{Hb}$ i mikrosirkulasjonen i vevene (venstreforskyvning av dissosiasjonskurven til $\mathrm{O}_{2} \mathrm{Hb}$ ) (7) (figur 1). Dette forsterker $\mathrm{O}_{2}$-mangelen i cellene, da $\mathrm{O}_{2}$ blir værende i sirkulasjonen. Til sist kan karbonmonoksid også binde seg til elektrontransportkjeden i mitokondriene (kompleks IV) og hemme utnyttelsen av $\mathrm{O}_{2}$ på cellenivå (6).

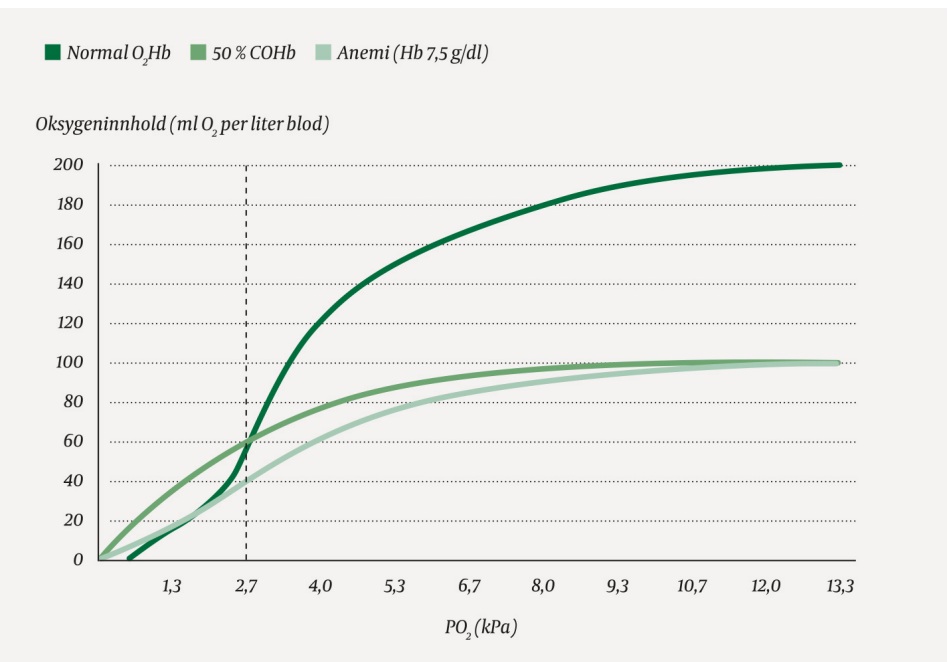

Figur 1 Oksygenets dissosiasjonskurve under normale forhold, ved $50 \%$ COHb og ved $50 \%$ anemi. Vertikal stiplet linje angir vevskritisk $\mathrm{pO}_{2}$. $\mathrm{CO}$ gir venstreforskyvning av dissosiasjonskurven. Ved $50 \%$ $\mathrm{COHb}$ vil derfor mer $\mathrm{O}_{2}$ fortsatt vare bundet til $\mathrm{Hb}$ og dermed vare utilgjengelig for vevene enn ved 
Hydrogencyanid og andre cyanogener hemmer cellenes evne til å utnytte $\mathrm{O}_{2}$ ved å binde seg til og blokkere elektrontransportkjedens kompleks IV i mitokondriene (8). Anaerob metabolisme med økende melkesyreproduksjon oppstår da selv om $\mathrm{O}_{2}^{-}$ transportmekanismene fra lunger til celler fungerer normalt. Klinisk bør derfor mistanken om cyanidforgiftning vekkes ved vedvarende melkesyreproduksjon (metabolsk acidose) og langsom klinisk bedring til tross for adekvat oksygenterapi $(9,10)$.

\section{Symptomatologi}

Generelt bør inhalasjonsskade mistenkes ved branner i lukkede rom der pasienten presenterer brannskader i ansikt, sot i luftveier og sputum, heshet, pipende respirasjon eller stridor (4). En samtidig systemisk forgiftning med karbonmonoksid (ev. cyanid) kan foreligge. Forgiftningene kan forekomme sammen, og dette ses typisk når cyanidforgiftning foreligger (10). De kliniske symptomene kan i tidlig fase også forveksles med angst, annen type intoksikasjon og influensaliknende sykdom $(11,12)$.

Både det raske forløpet som kan ses ved cyanidforgiftning (bevisstløshet/død i løpet av sekunder-minutter) (13), og det mer snikende bildet (minutter-timer) som oftest karakteriserer karbonmonoksidforgiftning (14), gjør at diagnostikken i stor grad avhenger av symptombildet. De kliniske effektene, og hvorvidt det oppstår alvorlig og irreversibel skade, avhenger av eksponeringsgrad og hvor raskt behandling iverksettes.

\section{LUFTVEISSYMPTOMER}

Takypné og dyspné ses hyppig og vil initialt være forårsaket av hypoksemi/hypoksi, men kan ledsages og forverres av bronkospasme og lungeødem grunnet brannrøykens direkte toksiske effekter på lungeparenkym eller sekundært til eventuell hjertesvikt (9, 14). Ved alvorlige forgiftninger kan pasienten utvikle bradypné eller apné, spesielt ved cyanidforgiftning (9).

\section{KARDIALE SYMPTOMER}

Initial takykardi kan ved alvorlig forgiftning slå over til bradykardi, med arytmier og hypotensjon. Hjertet kan da dekompensere fordi myokard blir iskemisk og aerob metabolisme ikke lenger kan opprettholdes $(9,15)$.

\section{NEVROLOGISKE SYMPTOMER}

De nevrologiske symptomene er i stor grad sammenfallende med symptomer på diffus cerebral hypoksi av andre årsaker, eksempelvis slik de kan ses ved hypoksemi under opphold i store høyder (16). Svimmelhet, hodepine, kvalme, kognitive problemer og utmattelse ses tidlig $(9,14)$. Ved mer alvorlig forgiftning kan det tilkomme synsforstyrrelser (mest typisk for CO) samt krampeanfall og bevissthetstap (både CO og HCN) $(9,14,17)$. Dersom bevissthetstapet primært skyldes cyanid, kan i tillegg lysstive pupiller, oppadvendt plantarrefleks og utslukkede dype senereflekser forekomme $(9,18)$. Andre nevrologiske sekveler med blant annet psykiatriske, kognitive eller motoriske forstyrrelser kan debutere i etterkant og er spesielt assosiert til karbonmonoksideksponering (6).

\section{HUDSYMPTOMER}

Hudrødme som følge av cyanid- og karbonmonoksidforgiftning er beskrevet i litteraturen. Klinisk gjenfinnes imidlertid dette i varierende grad, og manglende funn bør ikke tillegges vekt $(9,19)$.

\section{LUKT}

Karbonmonoksid er luktfri. Cyanid er beskrevet å lukte som bitre mandler (9), men evnen til å lukte cyanid er imidlertid ikke til stede hos alle (20). Manglende funn av cyanidlukt hos 


\section{Diagnostikk}

\section{KARBONMONOKSID}

Pålitelige blodgassanalyser hos slike pasienter krever at $\mathrm{O}_{2} \mathrm{Hb}$ og $\mathrm{COHb}$ (arteriell/ venøs) måles direkte, som i nyere blodgassmaskiner ved hjelp av et inkorporert CO-oksymeter (19). De fleste pulsoksymetere skiller ikke mellom $\mathrm{O}_{2} \mathrm{Hb}$ og $\mathrm{COHb}$ og kan derfor gi et falskt forhøyet bilde av pasientens oksygeneringsstatus (19).

COHb-konsentrasjoner $>10 \%$ ses nesten utelukkende ved forgiftninger (19). Lave COHbverdier ved innleggelse kan imidlertid ikke utelukke forgiftning, da COHb reduseres både av prehospital oksygenbehandling og tiden som har gått mellom eksponering og prøvetaking (19).

\section{CYANID}

Sikker diagnostikk av cyanidforgiftning krever påvisning av forhøyet cyanidnivå i blod. Slik analyse er tidkrevende (21), og tidsvinduet for effektiv behandling er smalt. Eventuell behandling må derfor starte før analyseresultatet foreligger. Et forhøyet laktatnivå i blodet (som avspeiler grad av vevshypoksi hos mange pasienter) brukes derfor ofte som et diagnostisk surrogat. Studier har vist at livstruende nivåer av cyanid i blodet $(>40 \mu \mathrm{mol} / \mathrm{l})$ gjenspeiles av et laktatnivå > $10 \mathrm{mmol} / \mathrm{l}$. I fravær av andre kjente årsaker (sjokk, hjertestans) har dette høy sensitivitet og spesifisitet for livstruende cyanidforgiftning (10).

\section{Behandling}

I prinsippet behandles CO-forgiftning ved å tilføre så mye oksygen at tettheten av $\mathrm{O}_{2}$ molekyler rundt Hb-molekylene oppveier affinitetsforskjellen og utkonkurrerer karbonmonoksid, slik at dannelse av $\mathrm{O}_{2} \mathrm{Hb}$ favoriseres fremfor $\mathrm{COHb}$.

Effekten blir større jo høyere forholdstallet mellom $p \mathrm{O}_{2}$ og $p \mathrm{CO}$ er. Normobar behandling med $100 \% \mathrm{O}_{2}$ (høy gasstrøm på maske med reservoar) er vist å redusere halveringstiden for $\mathrm{COHb}$ med ca. $75 \%$, og er grunnsteinen i behandlingen (22). Hyperbar oksygenbehandling i trykktank akselererer halveringstiden ytterligere og er antatt å kunne redusere forekomsten av nevrologiske sekveler etter forgiftning. En systematisk oversikt fra Cochrane-instituttet kunne imidlertid ikke bekrefte dette (6). Norske retningslinjer anbefaler likevel at hyperbar oksygenbehandling overveies ved alvorlig forgiftning og hos gravide (23).

Normobar behandling med $100 \% \mathrm{O}_{2}$ gis også ved cyanidforgiftning, selv om effekten er dårlig dokumentert (9). Ved cyanidforgiftning er raskest mulig tilførsel av antidot som kan binde eller nedbryte giften, livreddende behandling (9).

Hydroksykobalamin er det foretrukne antidotet på grunn av raskt innsettende effekt og få bivirkninger (9). Antidotet binder cyanid og danner cyanokobalamin ( $\left.B_{12}\right)$, som så skilles ut i urinen. Det kan gi rødrosa hudfarge, og ved høyere doser er det også observert blålilla fargeforandringer. Samtidig farges både urin og plasma rødt, hvilket kan interferere med visse typer blodprøveanalyser (9).

En annen type antidot er svoveldonoren natriumtiosulfat som virker ved å oppregulere kroppens primære nedbrytningsvei for cyanid, men effekten setter inn først etter noe tid (9). En tredje type antidot, nitritter, omgjør hemoglobin til methemoglobin, som igjen binder cyanidet. Grunnet risiko for alvorlig methemoglobinemi med medfølgende redusert bærerkapasitet av oksygen i blodet, anbefales ikke nitritter ved cyanidforgiftning etter røykinhalasjon (9). 


\section{LITTERATUR:}

1. Direktoratet for samfunnssikkerhet og beredskap. Brannstatistikk 2018.

https://www.dsb.no/reportasjearkiv/brannstatistikk-2018/ Lest 5.10.2019.

2. Levine MS, Radford EP. Fire victims: medical outcomes and demographic characteristics. Am J Public Health 1977; 67: 1077-8o. [PubMed][CrossRef]

3. Almersjö O, Ask E, Brandsjö K et al. Branden på passagerarfärjan Scandinavian Star den 7 april 1990. Stockholm: Socialstyrelsen, 1993.

https://www.socialstyrelsen.se/globalassets/sharepoint-dokument/artikelkatalog/ovrigt/1993-03-3.pdf Lest 5.10.2019.

4. Sheridan RL. Fire-related inhalation injury. N Engl J Med 2016; 375: 464-9. [PubMed][CrossRef]

5. Simonson M, Tuovinen H, Emanuelsson V. Formation of hydrogen cyanide in fires. A literature and experimental investigation. Brandforsk project 510-991. Stockholm: Sveriges provnings- och forskningsinstitut, 2000: 23-37.

6. Buckley NA, Juurlink DN, Isbister G et al. Hyperbaric oxygen for carbon monoxide poisoning. Cochrane Database Syst Rev 2011; nr. 4: CDoo2041. [PubMed]

7. Zwart A, Kwant G, Oeseburg B et al. Human whole-blood oxygen affinity: effect of carbon monoxide. J Appl Physiol 1984; 57: 14-20. [PubMed][CrossRef]

8. Stotz E, Altschul AM, Hogness T. The cytochrome c-cytochrome oxidase complex. J Biol Chem 1938; 124: 745-54.

9. Baud F, Steffens W, Borron S. Efficacy and safety of antidotes for acute poisoning by cyanides. Brussel: European Centre for Ecotoxicology and Toxicology of Chemicals, 2013.

10. Baud FJ, Barriot P, Toffis V et al. Elevated blood cyanide concentrations in victims of smoke inhalation. N Engl J Med 1991; 325: 1761-6. [PubMed][CrossRef]

11. Keyes DC. Medical response to terrorism: preparedness and clinical practice. Lippincott Williams \& Wilkins, 2005.

12. Dolan MC, Haltom TL, Barrows GH et al. Carboxyhemoglobin levels in patients with flu-like symptoms. Ann Emerg Med 1987; 16: 782-6. [PubMed][CrossRef]

13. Wexler J, Whittenberger JL, Dumke PR. The effect of cyanide on the electrocardiogram of man. Am Heart J 1947; 34: 163-73. [PubMed][CrossRef]

14. Burney RE, Wu SC, Nemiroff MJ. Mass carbon monoxide poisoning: clinical effects and results of treatment in 184 victims. Ann Emerg Med 1982; 11:394-9. [PubMed][CrossRef]

15. Satran D, Henry CR, Adkinson C et al. Cardiovascular manifestations of moderate to severe carbon monoxide poisoning. J Am Coll Cardiol 2005; 45:1513-6. [PubMed][CrossRef]

16. Lake Louise AMS Score Consensus Committee. The 2018 Lake Louise acute mountain sickness score. High Alt Med Biol 2018; 19: 4-6. [PubMed][CrossRef]

17. Mori T, Nagai K. Carbon-monoxide poisoning presenting as an afebrile seizure. Pediatr Neurol 2000; 22:330-1. [PubMed][CrossRef]

18. Bonsall JL. Survival without sequelae following exposure to $500 \mathrm{mg} / \mathrm{m} 3$ of hydrogen cyanide. Hum Toxicol 1984;3: 57-6o. [PubMed][CrossRef]

19. Hampson NB, Piantadosi CA, Thom SR et al. Practice recommendations in the diagnosis, management, and prevention of carbon monoxide poisoning. Am J Respir Crit Care Med 2012; 186: 1095-101. [PubMed][CrossRef]

20. Kirk RL, Stenhouse NS. Ability to smell solutions of potassium cyanide. Nature 1953; 171: 698-9. [PubMed][CrossRef]

21. Ma J, Dasgupta PK. Recent developments in cyanide detection: a review. Anal Chim Acta 2010; 673: 117-25. [PubMed][CrossRef]

22. Smollin C, Olson K. Carbon monoxide poisoning (acute). BMJ Clin Evid 2010; 2010: 12. [PubMed]

23. Håndbok i NBC medisin. Oslo: Nasjonalt kompetansesenter for NBC-medisin, 2011: 163-7.

https://www.helsebiblioteket.no/retningslinjer/håndbok-i-nbc-medisin Lest 5.10.2019. 
Publisert: 29. juni 2020. Tidsskr Nor Legeforen. DOI: 10.4045/tidsskr.19.0748 Mottatt 18.11.2019, første revisjon innsendt 11.3.2020, godkjent 19.5.2020.

(C) Tidsskrift for Den norske legeforening 2020. Lastet ned fra tidsskriftet.no 